\title{
Forced expression of E-cadherin in the mouse intestinal epithelium slows cell migration and provides evidence for nonautonomous regulation of cell fate in a self-renewing system
}

\author{
Michelle L. Hermiston, ${ }^{1}$ Melissa H. Wong, ${ }^{1}$ and Jeffrey I. Gordon ${ }^{2}$ \\ Department of Molecular Biology and Pharmacology, Washington University School of Medicine, St. Louis, Missouri 63110 \\ USA
}

The adult mouse small intestinal epithelium is self-renewing. Its crypt-villus unit provides a model for studying many of the processes that occur during tissue morphogenesis such as control of proliferative status, specification of cell fate, regulation of differentiation, and induction of death. To assess the contributions of cell-cell and cell-substratum interactions to the coordinated control of these processes, $129 / \mathrm{Sv}$ embryonic stem (ES) cells, transfected with a recombinant DNA consisting of a fatty acid-binding protein gene (Fabpl) promoter that functions along the entire length of the crypt-villus axis linked to mouse E-cadherin, were introduced into normal C57Bl/6 (B6) blastocysts. Analyses of adult B6 $\leftrightarrow 129 / \mathrm{Sv}$ mice indicated that forced expression of E-cadherin suppresses proliferation and induces apoptosis in the crypt, and slows cell movement up the villus. The slowed migration is not accompanied by a change in distribution of terminal differentiation markers along the crypt-villus axis suggesting that differentiation is largely cell nonautonomous. To determine whether the slowed migration was a direct effect of forced expression of E-cadherin or a secondary effect of reduced crypt cell production, another Fabp promoter was used to restrict overproduction of E-cadherin to the villus epithelium of transgenic mice. Enterocytic migration was slowed, although proliferation and apoptosis were not perturbed in crypts. Augmentation of cellular E-cadherin pools was accompanied by an increase in $\beta$-catenin levels. These findings establish that cadherins and their associated proteins modulate cellular migration, proliferation, and death programs in an adult vertebrate organ.

[Key Words: Cadherins; catenins; intestinal epithelium; migration; adhesion; differentiation; chimeric-transgenic mice]

Received January 12, 1996; revised version accepted March 5, 1996.

Decisions affecting proliferative status, lineage allocation, migration, differentiation, and death are made continuously and executed rapidly along the crypt-villus axis of the adult mouse small intestine. The ability to maintain coordinated control of these decisions and to monitor and preserve cellular census accurately are central features of this system. These features make the intestinal epithelium an attractive model for studying how tissue morphogenesis is regulated and how homeostasis is maintained when challenged by alterations in cell production, migration, or death.

Proliferation in the small intestinal epithelium is confined to the crypts of Lieberkühn. Each of the intestine's 1.1 million crypts contains $\sim 250$ epithelial cells. One or more active multipotent stem cells occupy a niche near

\footnotetext{
${ }^{1}$ These authors contributed equally to this study. ${ }^{2}$ Corresponding author.
}

the crypt base and give rise to a cohort of $\sim 150$ rapidly cycling $\left(T_{\mathrm{c}}=24 \mathrm{hr}\right)$ transit cells positioned in the midportion of the crypt (Potten and Loeffler 1990). Each villus is supplied by several crypts and has a steady-state census of 2000-8000 epithelial cells depending on its location along the duodenal-ileal axis (Wright and Irwin 1982). Absorptive columnar enterocytes, mucus-producing goblet cells, and enteroendocrine cells emerge from the crypt and complete their differentiation as they migrate up adjacent villi in vertical coherent columns. When mature cells approach the apical extrusion zone of the villus they enter a death program (Hall et al. 1994) and are exfoliated. The Paneth cell lineage also arises from the multipotent crypt stem cell. However, Paneth cells differentiate as they migrate down to the crypt base where they are eliminated by phagocytosis (Cheng 1974). Renewal is rapid; enterocytes, which comprise $>80 \%$ of epithelial cells, have a 3-day life span (Wright and Irwin 1982). 
One fundamental question about this system is whether epithelial cells are invested with complete responsibility for the control of their proliferation, migration, differentiation, and death programs. Cell autonomous decision making may be very hazardous in a selfrenewing tissue. If there is a perturbation in cell production, migration rate, or apoptosis/exfoliation, census control may be lost or a new set point (if achievable) may have to be tolerated. A cell nonautonomous system of governance may be required to ensure that homeostasis is maintained if there are disturbances in any of these programs.

Cell nonautonomous regulation can involve instructive cell-cell and cell-substratum interactions. Cell adhesion proteins represent one class of molecules that are important regulators of such dynamic interactions (Roskelley et al. 1995). Cadherins are single-pass transmembrane glycoproteins. Calcium-dependent, homotypic interactions between their extracellular domains results in the formation of cell adhesion "zippers" between adjacent cells (Overduin et al. 1995; Shapiro et al. 19951. Cadherins contain a conserved cytoplasmic domain that binds two structurally related cytosolic proteins, $\beta$-catenin and plakoglobin (Nagafuchi and Takeichi 1988; Ozawa et al. 1989, 1990; Jou et al. 1995|. $\alpha$-Catenin does not bind directly to cadherins but mediates interactions between cadherin $/ \beta$-catenin complexes or cadherin/plakoglobin complexes and the actin cytoskeleton, thereby allowing productive cell adhesion (Nagafuchi and Takeichi 1988; Ozawa et al. 1989|.

E-cadherin is the principal cadherin in the mouse intestinal epithelium and is produced by cells distributed along the length of the crypt-villus axis /Hermiston and Gordon 1995a). Mice homozygous for an E-cadherin null allele exhibit early embryonic lethality (Larue et al. 1994; Riethmacher et al. 1995). Disruption of the mouse $\beta$-catenin gene affects development of the embryonic ectoderm and also causes early lethality (Haegel et al. 1995). This early lethality highlights the importance of these molecules in development but hinders further analysis of their specific functions in adult tissues such as the intestine, which does not complete its morphogenesis until the third postnatal week (Schmidt et al. 1988; Calvert and Pothier 1990).

Recently we devised an approach for studying the contribution of cadherins and their associated proteins to the regulation of proliferation, adhesion/migration, differentiation, and death in the adult gut (Hermiston and Gordon 1995a,b). The 129/Sv embryonic stem (ES) cells are transfected with a recombinant DNA containing the gene of interest placed under the control of a promoter active at selected locations along the intestine's cryptvillus and duodenal-ileal axes. Stably transfected ES cells are then introduced into $\mathrm{C} 57 \mathrm{Bl} / 6$ (B6) blastocysts. Crypts in the resulting adult B $6 \leftrightarrow 129 / \mathrm{Sv}$ chimeric mouse intestine are monoclonal (i.e., they are populated by either B6 or 129/Sv cells but not by a mixture of both). The chimeric intestine contains patches of transgenic $129 / \mathrm{Sv}$ and normal B6 crypt-villus units. The $129 / \mathrm{Sv}$ patches can be identified readily in whole-mount prepa- rations of adult intestine because $129 / \mathrm{Sv}$ but not B6 enterocytes bind the lectin Ulex europeaus agglutinin type 1 (UEA 1). The B6 epithelium is used as an internal control for assessing the consequences of transgene expression. Polyclonal villi, positioned at boundaries of B6 and $129 / \mathrm{Sv}$ patches, contain cellular contributions from monoclonal 129/Sv crypts and monoclonal B6 crypts. This results in a juxtaposition of columns of $129 / \mathrm{Sv}$ and B6 cells on a single villus in a single chimeric animal (Fig. 1A), permitting even more precise assessment of the effect of the transgene. The combined use of low percent chimeric mice and promoters that only function in specific regions of the intestine offers the opportunity to manipulate expression of essential gene products, such as the cadherins and their affiliated proteins, without compromising the ability of the animal to survive through adulthood.

When a dominant-negative $\mathrm{N}$-cadherin mutant lacking an intact extracellular domain (NCADS; Kintner 1992) was only expressed in villus-associated enterocytes, endogenous E-cadherin levels decreased dramatically and the protein was lost from the cell surface (Hermiston and Gordon 1995a). Cell-cell and cell-substratum contacts were disrupted. Migration rates up the villus increased. Cells lost their differentiated polarized phenotype and precociously entered a death program. When a different promoter was used to force expression of NCAD $\triangle$ in both the crypt and villus, an inflammatory bowel disease developed that was confined to $129 / \mathrm{Sv}-$ NCAD $\triangle$ epithelium. NCAD $\perp$ expression also perturbed proliferation, migration, and death programs in the crypts, leading to adenomas (Hermiston and Gordon 1995bl. We have now performed the reciprocal experiment. Rather than depleting E-cadherin, we have examined the consequences of overexpressing the protein.

\section{Results}

Generation of $B 6 \leftrightarrow 129 / S_{V}-E C A D$ mice

Experiments in transgenic and B6 $\leftrightarrow 129 /$ Sv chimerictransgenic mice have shown that nucleotides -596 to +21 of a rat fatty acid-binding protein gene (Fabpl) can be used to direct expression of a variety of reporters to the small intestine's four principal epithelial cell lineages (Trahair et al. 1989; Hermiston et al. 1993; Kim et al. 1993; Hermiston and Gordon 1995b). Expression is initiated in undifferentiated cells located near the crypt's stem cell zone, is sustained as cells complete their migration-associated differentiation, and is evident in mature cells up to the time of their removal by death/exfoliation. Fabpl reporter transgenes are expressed at highest levels in the proximal jejunum. Transgene expression is first observed on embryonic day 15 , coincident with initial cytodifferentiation of the small intestine's pseudostratified endoderm to an epithelial monolayer, and is sustained through the first 2 years of life.

The Fabpl promoter was used to force expression of mouse E-cadherin in the ES cell-derived intestinal epithelium of B6 $\leftrightarrow 129 / \mathrm{Sv}$ chimeras. $129 / \mathrm{Sv}$ D3 ES cells, 

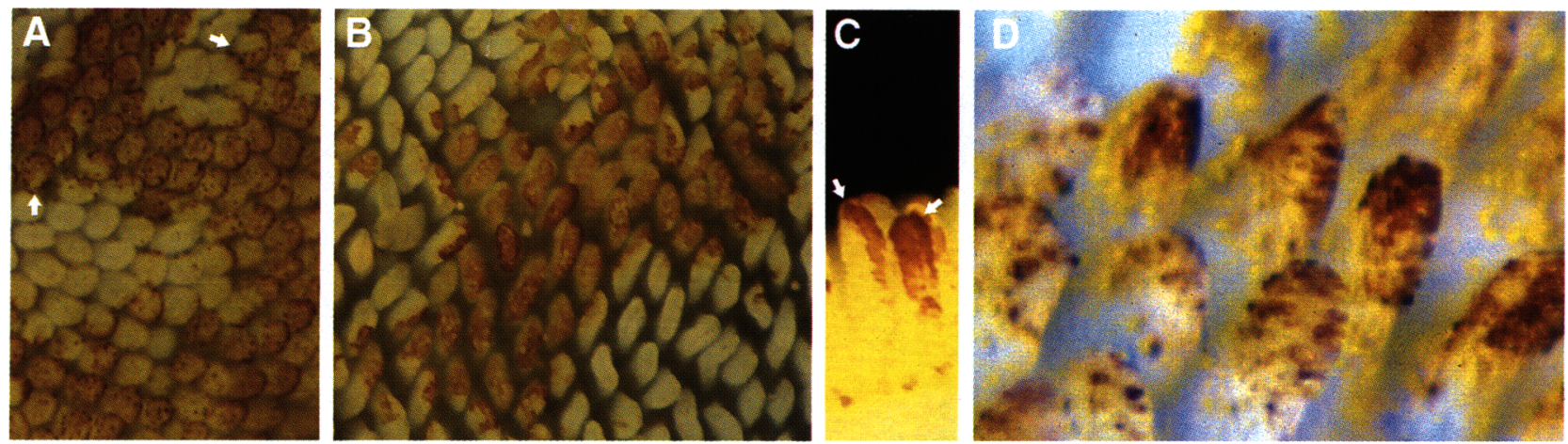

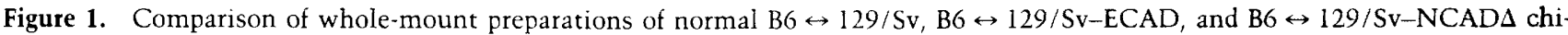
meric intestines. (A) Proximal jejunum from a normal 6 -month-old B6↔129/Sv mouse. The tissue was incubated with peroxidaseconjugated UEA l. Bound lectin was visualized with 3'3'-diaminobenzidene. The $129 /$ Sv enterocytes and a subset of B6 goblet cells bind the lectin and appear brown. The B6 enterocytes do not bind the lectin and appear white. Polyclonal villi, supplied by monoclonal B6 and monoclonal 129/Sv crypts, are located at the borders of these patches (arrows). (B) Jejunum from a 6-month-old B6 $\leftrightarrow 129 /$ Sv-ECAD mouse. Overall villus height and shape are the same in adjacent 129/Sv-ECAD and B6-derived patches. (C) Side view of polyclonal villi shown in $B$. UEA ${ }^{+} 129 /$ Sv-ECAD enterocytes (brown) migrate up the villi in coherent columns (arrows). (D) High power view of jejunal villi from a 6 -month-old $\mathrm{B} 6 \leftrightarrow 129 / \mathrm{Sv}-\mathrm{NCAD}\lrcorner$ mouse. The migration of UEA $1^{+}$enterocytes up the villus is disorganized.

stably transfected with an Fabpl/E-cadherin transgene (ECAD), were introduced into B6 blastocysts. Two independent ES cell lines were used to generate chimeras. The $129 /$ Sv contribution to coat color ranged from $20 \%$ to $50 \%$. There were no detectable differences in the growth rates or adult body weights of specific pathogenfree (SPF) B6 $\leftrightarrow 129 / \mathrm{Sv}-\mathrm{ECAD}$ and normal B6 $\leftrightarrow 129 / \mathrm{Sv}$ animals.

Villus morphology, cell migration pathways, and cell-cell contacts are not affected

Whole-mount preparations of small intestine from 1.5and 6-month-old B6↔ $129 / \mathrm{Sv}-\mathrm{ECAD}$ chimeras were stained with UEAl $(n=2-4$ animals from each ES cell line/time point). The height and shape of villi in adjacent $129 / \mathrm{Sv}-\mathrm{ECAD}$ and B6 patches were similar (Fig. $1 \mathrm{~B}$ |, suggesting that cellular census was not grossly perturbed in $129 / \mathrm{Sv}-\mathrm{ECAD}$ villi.

Polyclonal villi, supplied by monoclonal $\mathrm{B} 6$ crypts and monoclonal $129 / \mathrm{Sv}-\mathrm{ECAD}$ crypts, were encountered at the boundary between $\mathrm{UEAl}^{-}$and $\mathrm{UEAl}^{+}$patches. The appearance of these polyclonal villi was similar in B6 $\leftrightarrow 129 /$ Sv-ECAD and control B6 $\leftrightarrow 129 /$ Sv animals (Fig. 1A,B). There were no abnormalities apparent in the organization of cellular migration pathways. Vertical columns of confluent, closely juxtaposed UEAl ${ }^{+} 129 /$ Sv-ECAD epithelial cells extended from the base of a polyclonal villus to its tip (Fig. 1C). The width of $129 /$ Sv-ECAD columns was similar to the width of $129 / \mathrm{Sv}$ columns in jejunal polyclonal villi from normal 1.5to 6-month-old B6 $\leftrightarrow 129 / \mathrm{Sv}$ chimeras (Fig. 1A-C). In contrast, forced expression of NCADS produces gaps between adjacent enterocytes (Hermiston and Gordon $1995 \mathrm{a}, \mathrm{b})$ and disorganized migration up the villus (Fig. 1D).
Hematoxylin and eosin (H\&E)-stained sections of 129/ Sv-ECAD jejunal villi revealed no detectable disruptions of cell-cell or cell-substratum contacts or mucosal inflammation $(n=10-13$ mice/cell line; 1.5 and 6 months old). The intracellular distribution and concentration of the tight junction-associated protein $\mathrm{ZO}-1$ was similar in adjacent B6 and 129/Sv-ECAD crypt-villus units, providing further evidence of the integrity of cell-cell contacts (data not shown).

\section{Cell migration is slowed}

The distance cells migrated along the crypt-villus axis per unit time was defined in 1.5- and 6-month-old B6 $\leftrightarrow 129 / \mathrm{Sv}-\mathrm{ECAD}$ and B6 $\leftrightarrow 129 / \mathrm{Sv}$ cage mates. Mice were given a single intraperitoneal injection of 5-bromo2 '-deoxyuridine $(\mathrm{BrdU})$ to label crypt epithelial cells during S-phase $(n=2-6 \mathrm{mice} / \mathrm{time}$ point $/$ cell line). Animals were sacrificed $1.5-96 \mathrm{hr}$ later. Sections of proximal jejunum were incubated with anti-BrdU sera to visualize the distance that BrdU-labeled cells had migrated from the crypt. Analysis of control B6↔129/Sv mice revealed no differences in the location of the leading edges of $\mathrm{BrdU}^{+}$enterocytes in adjacent $129 / \mathrm{Sv}$ and $\mathrm{B} 6 \mathrm{col}^{-}$ umns (Fig. 2A). This was not the case in the polyclonal villi of $\mathrm{B} 6 \leftrightarrow 129 / \mathrm{Sv}-\mathrm{ECAD}$ chimeras. BrdU ${ }^{+} \mathrm{B} 6$ enterocytes reached a higher cell stratum than $\mathrm{BrdU}^{+}$enterocytes in adjacent 129/Sv-ECAD columns. On the basis of data obtained at the 1.5-, 12-, 48-, 60-, 72-, and 96-hr time points (e.g., Fig. $2 \mathrm{~B}, \mathrm{C}$ ), we concluded that there was a 12- to 24 -hr slowing in the migration of $129 / \mathrm{Sv}-\mathrm{ECAD}$ cells.

Immunohistochemical surveys using antibodies to laminin, type IV collagen, fibronectin, and heparin sulfate proteoglycans failed to disclose any differences in the levels or distributions of these molecules in the B6 
Figure 2. Forced expression of E-cadherin slows epithelial migration rates along the crypt-villus axis. (A) Polyclonal villus from the proximal jejunum of a normal 6-month-old B6 $\leftrightarrow 129 / \mathrm{Sv}$ mouse, injected with BrdU $48 \mathrm{hr}$ before sacrifice. The section was incubated with goat anti-BrdU [visualized as magenta with indocarbocyanine (Cy3)-donkey anti-goat Igl and FITCconjugated UEA1. Nuclei were stained with bis-benzimide (dark blue). FITCUEAl binds to glycoconjugates at the surface of $129 / \mathrm{Sv}$ villus enterocytes (green) and to 129/Sv and B6 Paneth cells (aqua). $\mathrm{BrdU}^{+}$cells in the adjacent UEA1 ${ }^{-} \mathrm{B} 6$ and $\mathrm{UEA}^{+} 129 / \mathrm{Sv}$ columns have traveled the same distance up the villus (arrows). $\mathrm{BrdU}^{+} / \mathrm{UEAl}^{+}$Paneth cells have $\mathrm{mi}-$ grated to the crypt base (arrowheads). $(B, C)$ Polyclonal jejunal villi from 6-month-old
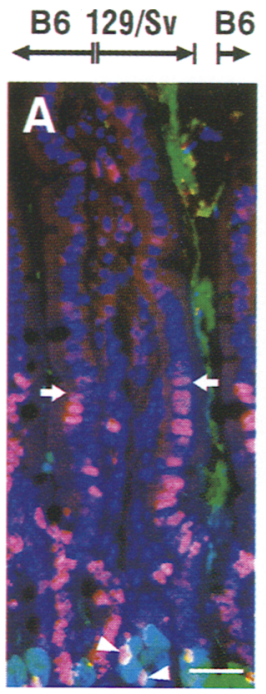
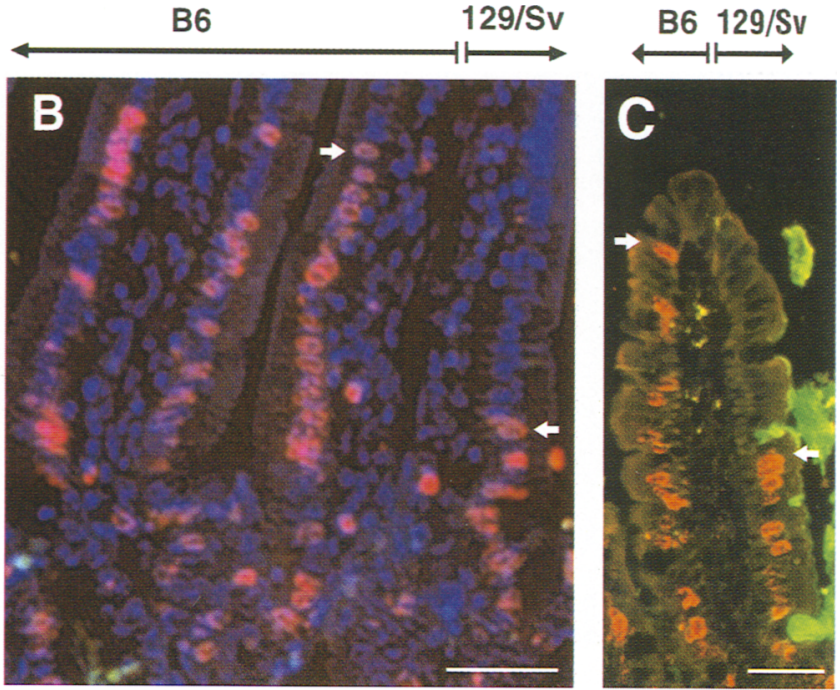
B6 $\leftrightarrow 129 /$ Sv-ECAD chimeras. BrdU was given $48 \mathrm{hr}(B)$ and $60 \mathrm{hr}(C)$ before sacrifice. The sections were processed as in $A$ except that in $B$ UEA-1 was omitted (cells were genotyped by staining adjacent serial $5-\mu \mathrm{m}$ sections of the villus with the lectin), and in $C$ bis-benzimine was not included. The slower migration of $129 / \mathrm{Sv}-\mathrm{ECAD}$ enterocytes can be appreciated by noting the difference in location of the leading edges (arrows) of BrdU ${ }^{+}$ enterocytes in adjacent B6 and 129/Sv columns. Bars, $25 \mu \mathrm{m}$.

and $129 / \mathrm{Sv}-\mathrm{ECAD}$ components of polyclonal villi or between jejunal villi located in adjacent B6 and 129/SvECAD patches (data not shown). Thus, the change in migration distance could not be correlated with any change in the concentrations of these major components of the epithelium's basement membrane.

\section{Proliferation and death programs are perturbed}

We compared the number and location of $M$-phase and apoptotic cells in adjacent 129/Sv-ECAD and B6 jejunal crypts of 6-month-old chimeras to determine whether the reduced migration rate was associated with a reduced rate of crypt cell production. The number of $\mathrm{M}$-phase cells was diminished in $129 / \mathrm{Sv}-\mathrm{ECAD}$ crypts. The reduction was statistically significant $(P<0.05)$ in the middle third of the crypt where the proliferating transit cell population resides (Fig. 3A). Comparisons of $129 / \mathrm{Sv}$ and B6 jejunal crypts in normal age-matched chimeras failed to reveal any significant strain-specific differences in the number or location of $M$-phase cells (data not shown).

A statistically significant increase in apoptosis was also documented in proximal jejunal $129 / \mathrm{Sv}-\mathrm{ECAD}$ crypts $(P<0.05$; Fig. $3 \mathrm{~B})$. The increase was most pronounced in the upper two-thirds of the crypt (e.g., fivefold comparing the upper third of adjacent $129 / \mathrm{Sv}-$ ECAD and $\mathrm{B} 6$ crypts) (Fig. $3 \mathrm{~B}$ ). In contrast, no differences in apoptosis were noted between 129/Sv-ECAD and B6 villi. Surveys of normal B6 $\leftrightarrow 129 / \mathrm{Sv}$ chimeras confirmed that there were no strain-specific differences in the frequency or distribution of apoptotic epithelial cells (data not shown).

\section{Slowing of cell migration is a primary effect of forced expression of E-cadherin}

Slowed migration could be a secondary effect of dimin- ished proliferation and increased apoptosis. If fewer cells exited the crypt, there would be a reduced rate of movement up the villus. Alternatively, the slowed migration could be a primary effect of forced expression of E-cadherin. This issue was addressed by generating FVB/N
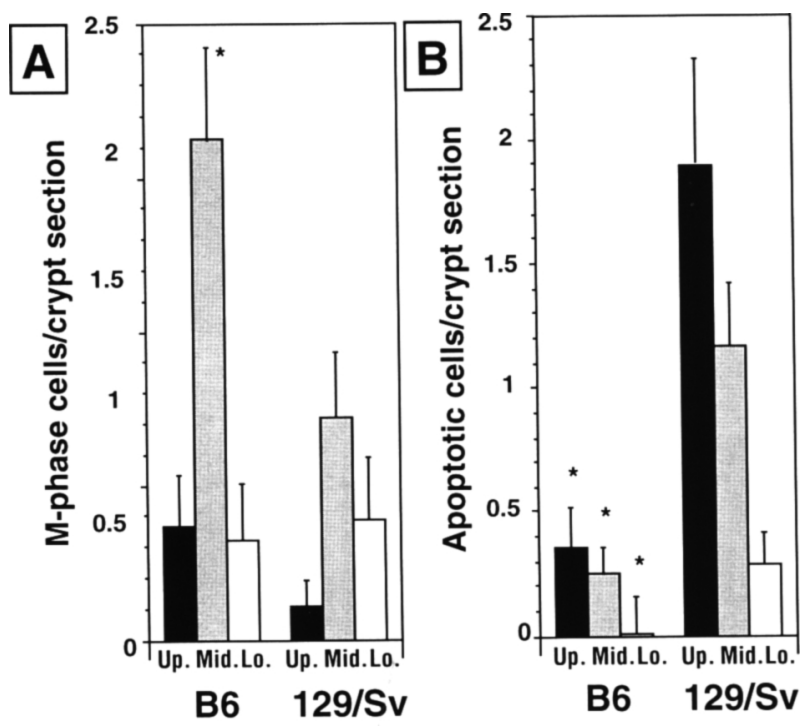

Figure 3. Forced expression of E-cadherin is associated with a reduction in crypt proliferation and an increase in apoptosis. $(A)$ Frequency and distribution of proliferating ( $M$-phase) cells in crypts located within adjacent patches of B6 and 129/Sv-ECAD epithelium. Crypts were divided into upper (Up.), middle (Mid.), and lower (Lo.) thirds. Mean values \pm S.E. are plotted for 6-month-old chimeras. $(B)$ Average number and position of apoptotic cell bodies in 129/Sv-ECAD and B6 crypts. Asterisks indicate that the difference between $B 6$ and $129 / \mathrm{Sv}$ crypts is statistically significant $(P<0.05)$. 
transgenic mice where forced expression of E-cadherin was limited to postmitotic villus enterocytes. The restricted pattern of $\mathbf{E}$-cadherin expression was engineered by linking nucleotides -1178 to +28 of a homologous rat fatty acid-binding protein gene (Fabpi) to mouse E-cadherin. Like Fabpl -596 to +21, Fabpi $^{-1178}$ to +28 is activated on embryonic day 15 , remains active for at least the first 2 years of postnatal life, and exhibits highest activity in the jejunum (Kim et al. 1993).

A reverse transcriptase-PCR assay confirmed the expected pattern of Fabpi-ECAD expression along the duodenal-ileal axis in 1- to 6-month-old mice /data not shown|. By using transgenic as opposed to chimeric mice, we were able to quantitate changes in the steadystate levels of E-cadherin and catenins. Western blot analysis of jejunal proteins recovered from adult members of an expressing pedigree revealed that the concentrations of E-cadherin and $\beta$-catenin were increased three- and fivefold, respectively, compared to their agematched normal littermates (Fig. 4E,F). $\alpha$-Catenin levels increased less than twofold, whereas actin levels remained constant (Fig. 4G; data not shown).

Transgenic animals and their nontransgenic littermates were pulse labeled with BrdU and sacrificed 1.5$96 \mathrm{hr}$ later ( $n=2-4 \mathrm{mice} /$ group). A reduction in cell migration rate was observed in transgenic jejunal villi that was comparable in magnitude to that observed in chimeric-transgenic mice (Fig. 4A,B). The slowing of cellular migration was not accompanied by a reduction in crypt cell proliferation or an increase in apoptosis (Fig. 4C,D). Villus morphology appeared normal. There were no statistically significant changes in small intestinal weight [mean \pm S.D. $2.9 \pm 0.7 \mathrm{~g}(n=$ twelve $1.5-$ to 6-month-old transgenics) versus $2.9 \pm 0.5 \mathrm{~g}(n=12$ normall) or in total body weight $[25.8 \pm 7 \mathrm{~g}$ (transgenic) versus $28.0 \pm 5.7 \mathrm{~g}$ (normal)]. These results establish that
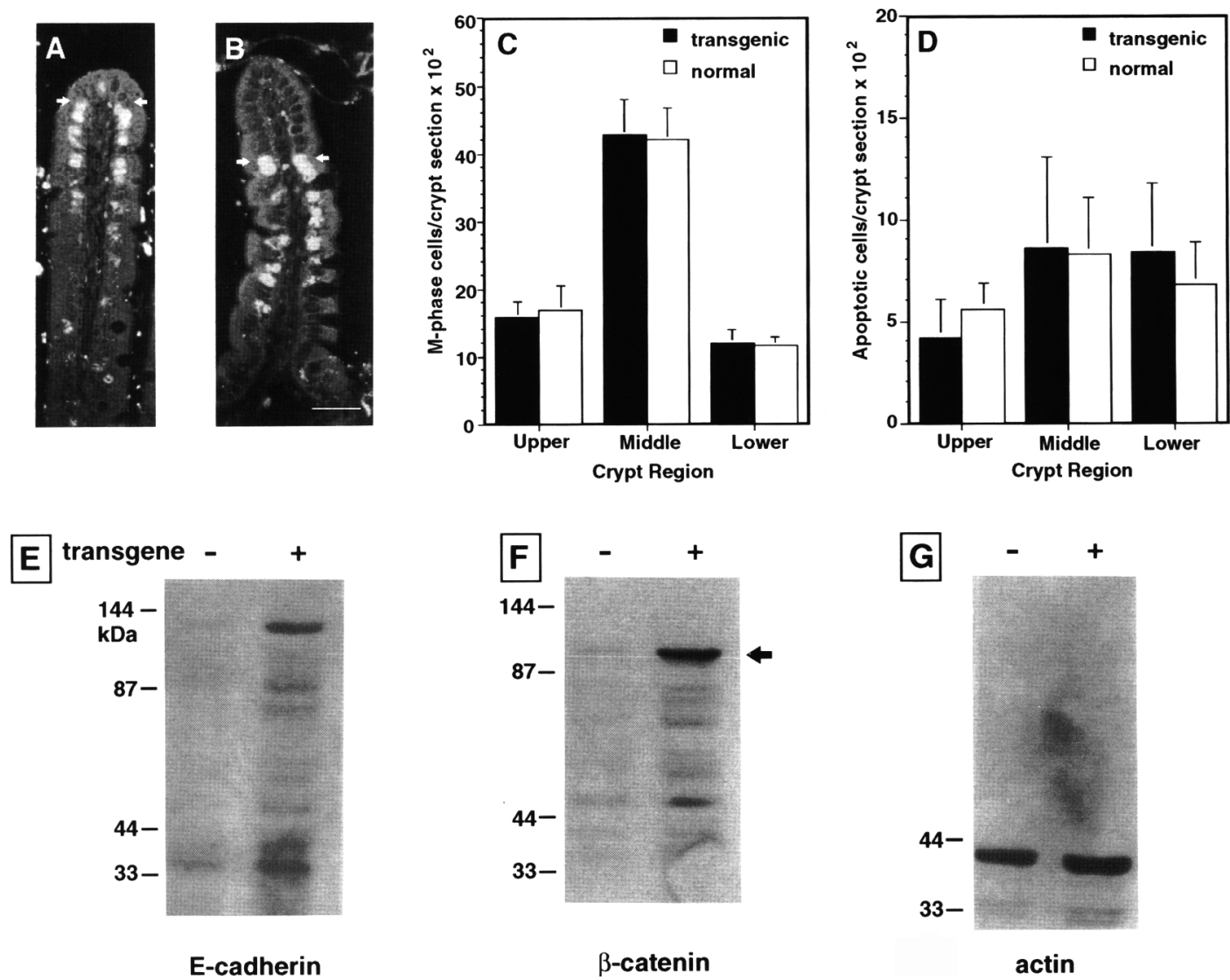

Figure 4. Forced expression of E-cadherin in the villus epithelial cells of Fabpi-ECAD transgenic mice slows their migration. $(A, B)$ Comparison of cell migration in the proximal jejunum of normal $|A|$ and transgenic $(B)$ littermates. Cage mates were given an injection of BrdU $72 \mathrm{hr}$ before sacrifice. Sections were prepared from proximal jejunal segments recovered at identical distances from the gastroduodenal junction and then incubated with goat anti-BrdU, Cy3-donkey anti-goat Ig, and bis-benzimide. Comparison of the leading edges of $\mathrm{BrdU}^{+}$cells (arrows) establishes that forced expression of ECAD in villus enterocytes slows their migration. (C,D) Number of $\mathrm{M}$-phase and apoptotic cells in proximal jejunal crypts of normal and transgenic mice. Mean values $\pm S$.E. are plotted. (E-G) Blots of total proximal jejunal proteins extracted from normal and transgenic littermates raised in the same microisolator cages. Segments of jejunum were harvested at identical distances from the gastroduodenal junction. Proteins ( $100 \mu \mathrm{g} /$ lane) were fractionated by SDS-PAGE. Blots were probed with antibodies to E-cadherin, $\beta$-catenin, and actin. Arrows point to the intact immunoreactive protein. 
slowing of epithelial cell migration is a direct consequence of forced expression of E-cadherin.

\section{Evidence suggesting that differentiation along the crypt-villus axis is largely cell nonautonomous}

If differentiation is entirely autonomous, expression of terminal differentiation markers should be determined by the time that has elapsed since cells exit the cell cycle and are allocated to a given lineage and not by the position they occupy along the crypt-villus axis. In this conceptualization of entirely cell autonomous control, a slowing of epithelial cell migration should result in expression of terminal differentiation markers in the crypt that would be expressed normally only on the villus.

The distribution of a variety of differentiation markers was defined along the crypt-villus axis in 1.5- and 6 -month-old B6 $\leftrightarrow 129 / \mathrm{Sv}-\mathrm{ECAD}$ mice. Production of liver (L-) and intestinal (I-) fatty acid-binding proteins (FABPs) is initiated in members of the enterocytic lineage just as they reach the crypt-villus junction. L-FABP and I-FABP levels are maintained until cells are eliminated at the villus tip. Immunostaining of $\mathrm{B} 6 \leftrightarrow 129 / \mathrm{Sv}-$ ECAD villi indicated that slowing cellular migration rates did not result in FABP expression in crypts (Fig. $5 \mathrm{~A}, \mathrm{~B} \mid$. UEAl recognizes fucosylated glycoconjugates produced by $129 / \mathrm{Sv}-\mathrm{ECAD}$ enterocytes when they emerge from the crypt (Fig. 5B), as it does in normal B6 $\leftrightarrow 129 / \mathrm{Sv}$ chimeras (Fig. 5C). Substance P, serotonin, and secretin are expressed sequentially as enteroendocrine cells migrate from jejunal crypts to the tips of villi (Roth and Gordon 1990). The distribution of these markers was the same in the $129 / \mathrm{Sv}-\mathrm{ECAD}$ and $\mathrm{B} 6$ components of poly- clonal crypt-villus units (data not shown). Paneth cells express lysozyme, antimicrobial peptides (cryptdins), and fucosylated glycoconjugates after they execute their downward migration and differentiation (Bry et al. 1994). Lysozyme- and cryptdin-producing UEA ${ }^{+}$Paneth cells were confined to the base of $129 / \mathrm{Sv}-\mathrm{ECAD}$ jejunal crypts, just as they were in adjacent $\mathrm{B} 6$ crypts (Fig. 5A,B; data not shownl.

Glycoconjugates recognized by a variety of lectins, including UEA1, represent sensitive markers of the differentiation programs of the intestine's four epithelial lineages (Falk et al. 1994). The cell lineage and crypt-villus patterns of Dolicos biflorus agglutinin, Jacalin-1, Glycine max agglutinin, and Helix pomentia agglutinin binding were not perturbed in 129/Sv-ECAD epithelium (Fig. 5D,E).

Together these data are consistent with the notion that differentiation along the crypt-villus axis is not cell autonomous. The data also indicate that lineage allocation is not perturbed by forced expression of E-cadherin in crypts, even in the face of altered proliferation and death.

A more slowly moving epithelial cell may have an increased chance of acquiring mutations that lead to intestinal neoplasia. Moreover, disruption of endogenous cadherin function can result in neoplasia. When the Fabpl promoter was used to express NCAD $\Delta$, mice develop dysplasia in their 129/Sv but not B6 small intestinal epithelium by 4-6 weeks of age and adenomas as early as 12 weeks (Hermiston and Gordon 1995b). When the same promoter was used to force expression of ECAD, no dysplasia or neoplasia was observed after 24 30 weeks $(n=10$ mice/ES-ECAD cell line).
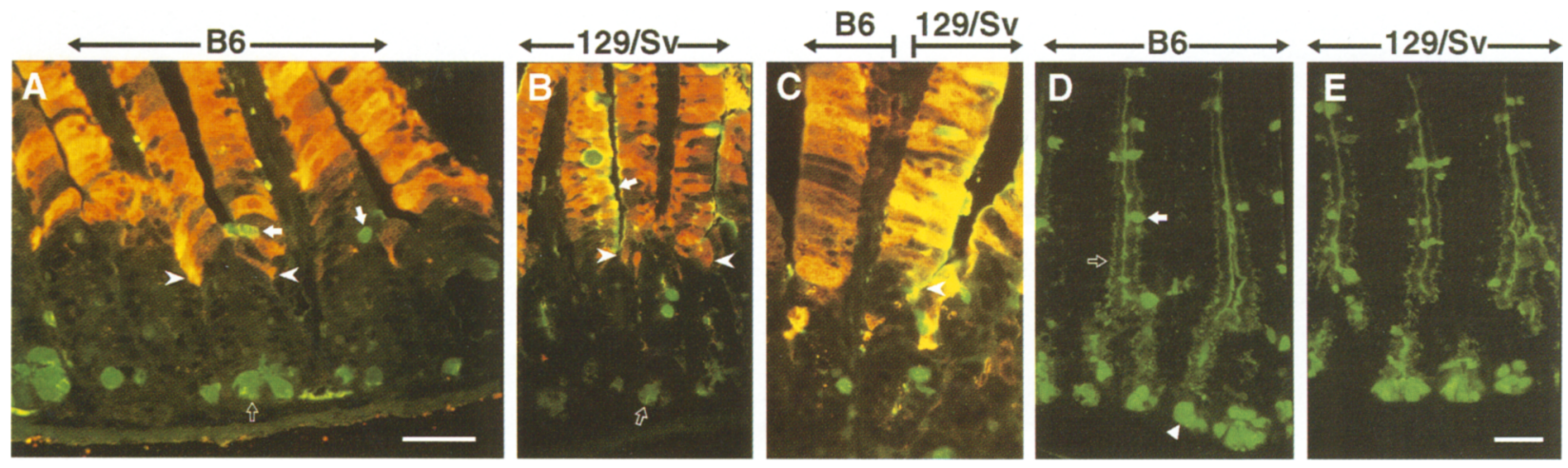

Figure 5. Evidence for cell nonautonomous differentiation along the cryptvillus axis. $|A, B|$ Sections prepared from adjacent patches of B6 and 129/Sv-ECAD proximal jejunal crypt-villus units. Sections were incubated with FITC-UEA1, rabbit anti-L-FABP, and Cy3-donkey anti-rabbit Ig. (A) The lectin reacts with Paneth cells located at the base of crypts (open arrow) and with a subset of goblet cells (closed arrows). L-FABP (orange) first appears in enterocytes after they exit B6 crypts and arrive at the base of the villus. A crypt-villus junction is denoted with closed arrowheads. $(B)$ These crypt-villus units are genotyped as 129/Sv because FITC-conjugated UEAl (green) binds to the surface and supranuclear Golgi apparatus of villus enterocytes (closed arrow). Although 129/Sv-ECAD epithelial cells migrate more slowly, L-FABP is not expressed precociously in the crypts. $(C)$ Jejunal polyclonal villus from a normal $\mathrm{B} 6 \leftrightarrow 129 / \mathrm{Sv}$ chimera, processed as in $C$. UEA ${ }^{+} / \mathrm{L}_{-\mathrm{FABP}}{ }^{-}$enterocytes first appear at the crypt-villus junction. $(D, E)$ Adiacent patches of B6 and 129/Sv crypt-villus units in the proximal jejunum of a 6 -month-old B6 $\leftrightarrow 129 / \mathrm{Sv}$-ECAD mouse. Sections were incubated with FITC-conjugated $H$. pomentia agglutinin, which recognizes glycoconjugates produced by Paneth cells (arrowhead in $D$ ), enterocytes (open arrow pointing to the cell's supranuclear Golgi apparatus) and a subset of goblet cells (closed arrow). Bar, $25 \mu \mathrm{m}$. 
Intracellular distribution of $\beta$-catenin is perturbed by forced expression of NCAD」 but not ECAD

Incubation of sections of proximal jejunum from normal 1.5- to 6-month-old B6 $\leftrightarrow 129 / \mathrm{Sv}$ mice with an E-cadherin monoclonal antibody disclosed intense staining at the apical junctional complexes, weaker staining along the lateral and basilar surfaces of villus epithelial cells, and very weak to absent cytoplasmic staining (Fig. 6A). A different intracellular distribution was noted in crypt epithelial cells where basilar staining is weak and apical staining is very intense (Fig. 6B,C). Like E-cadherin, $\alpha$ and $\beta$-catenin exhibit differentiation-associated changes in location. In crypts, apical staining is more intense than on basilar or lateral surfaces; in villi, both proteins are concentrated at the basolateral cell surfaces and at apical junctional complexes (Fig. 6D-F). Normal 129/Sv and B6 epithelial cells, located at a given stratum of adjacent crypt-villus units or within a polyclonal villus, have similar intracellular distributions and levels of E-cadherin, $\alpha$-catenin, and $\beta$-catenin (data not shown).

Forced expression of E-cadherin by the Fabpl promoter produced no detectable change in its intracellular distribution (Fig. 6A,G) or in the distributions of $\alpha$ - or $\beta$-catenin within crypt and villus epithelial cells (Fig. 6D,H; data not shown). Forced expression of NCAD $\Delta$ by the same Fabpl promoter depleted cells of E-cadherin /see introductory section) and had a selective effect on catenins. NCAD $\Delta$ did not change the intracellular location or level of $\alpha$-catenin in crypt-villus units. However, $\beta$-catenin was lost from the surfaces of villus epithelial cells and redistributed to their cytoplasm and to a region normally occupied by the Golgi apparatus (Fig. 6I). These changes became more pronounced as enterocytes completed their migration to the villus tip (Fig. 6J). $\beta$-Catenin
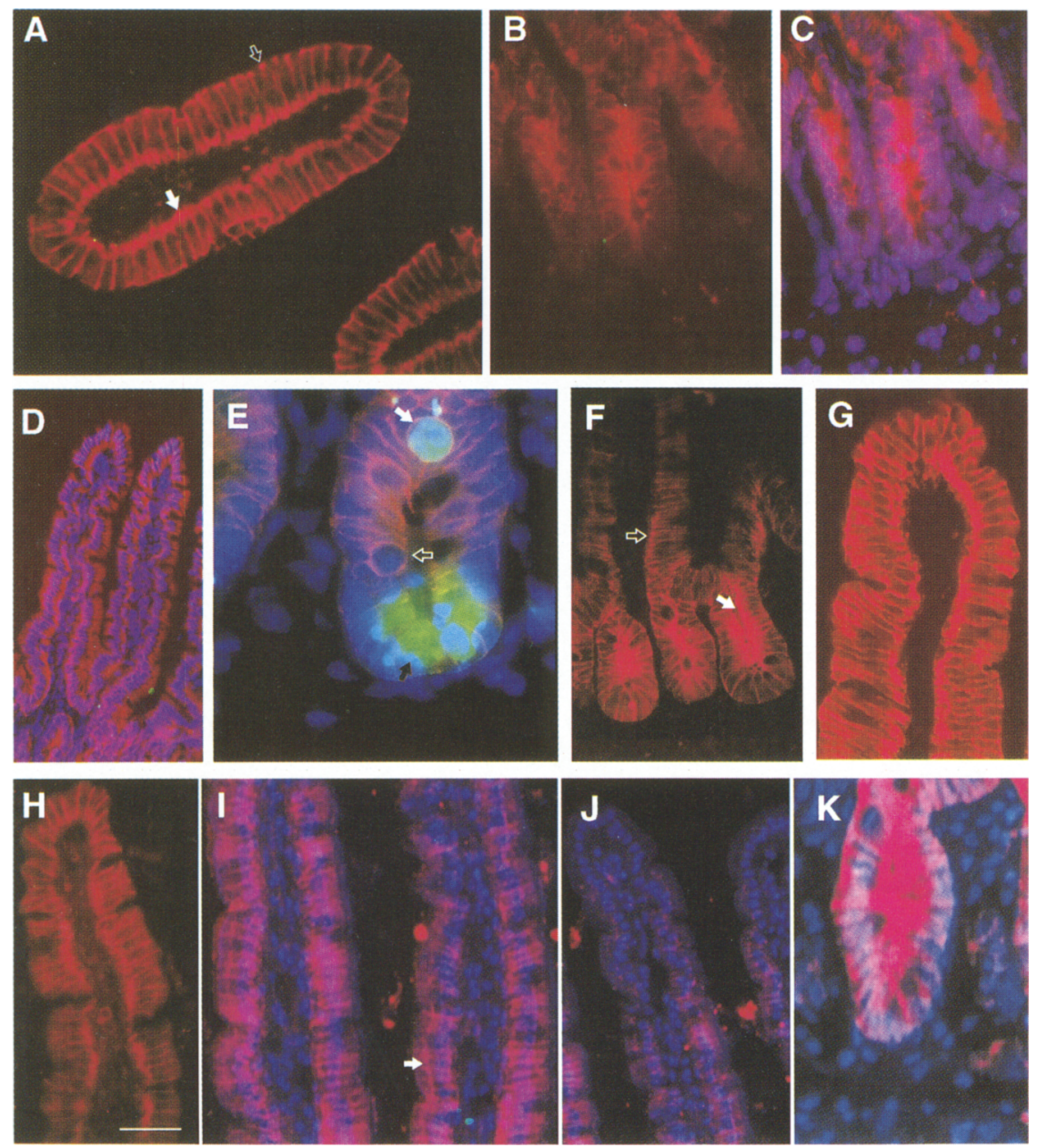

Figure 6. The intracellular distributions of E-cadherin, $\alpha$-catenin, and $\beta$-catenin in normal $\quad$ B6 $\leftrightarrow 129 / S v, \quad$ B6 $\leftrightarrow 129 / S v-$ $\mathrm{ECAD}$, and $\mathrm{B} 6 \leftrightarrow 129 / \mathrm{Sv}-\mathrm{NCAD} \Delta$ intestine. Sections were prepared from the proximal jejunums of 6-month-old chimeras. (A) Villi from a normal B6↔129/Sv mouse sectioned perpendicular to the crypt-villus axis and stained with a rat $\mathrm{E}$-cadherin $\mathrm{mAb}$ and $\mathrm{Cy} 3$-donkey anti-rat Ig. Note the intense staining at the basolateral surface (closed arrow) and apical junctional complexes (open arrow). (B) Jejunal crypt from the same mouse as in $A$, stained with the same reagents. $|C|$ Dual exposure of the crypt shown in $B$ after staining nuclei with bis-benzimide. In contrast to villus epithelial cells, E-cadherin is located predominantly on the apical surfaces of proliferating and nonproliferating undifferentiated crypt cells. $(D)$ B6 crypt-villus unit stained with rabbit anti$\beta$-catenin, Cy3-donkey anti-rabbit Ig, and bis-benzimide. (E) B6 crypt processed as in $D$ but with the addition of FITC-UEAl. $\beta$-Catenin levels are considerably higher at the lateral and apical cell surfaces of crypt epithelial cells than at their basilar surfaces. UEAl ${ }^{+}$Paneth cells at the crypt base appear aqua (open arrow). Lectin-positive (closed arrow) and -negative goblet cells (open arrow) are evident. $(F)$ B6 cryptvillus unit stained with rabbit anti- $\alpha$-catenin and Cy3-donkey anti-rabbit Ig. The apical surfaces of crypt cells are intensely stained (closed arrow), in contrast to villus epithelial cells where immunoreactive protein is more prominent at the basolateral surface (open arrow). Overall cellular concentrations of $\alpha$-catenin appear to diminish as cells migrate up the villus. $(G)$ Intracellular distribution of E-cadherin in a $129 / \mathrm{Sv}-\mathrm{ECAD}$ villus. The pattern is similar to that seen in the normal B6 villus shown in $A$. $(H) \beta$-Catenin accumulation in $129 / \mathrm{Sv}$-ECAD epithelial cells. Comparison with $D$ reveals a similar intracellular distribution. $(I-K)$ Views of a $129 / \mathrm{Sv}-\mathrm{NCAD} \mathrm{s}$ crypt-villus unit stained with anti- $\beta$-catenin and bis-benzimide. Expression of NCAD $\Delta$ is associated with a redistribution of $\beta$-catenin from the surfaces of villus epithelial cells to their cytoplasm and to the area of their supranuclear Golgi apparatus (arrow in $I$ ). Total cellular $\beta$-catenin levels are reduced in the upper portion of the villus $(/)$. $\beta$-Catenin distribution in crypt epithelial cells is shown in $K$. Bar, $25 \mu \mathrm{m}$. 
was also redistributed to the cytoplasm in crypt cells and there was an apparent increase in total pool size, especially in areas of dysplasia or within adenomas (Fig. $6 \mathrm{C}, \mathrm{K}_{\text {; }}$ data not shown; Hermiston and Gordon 1995b|.

\section{Discussion}

Forced expression of E-cadherin along the crypt-villus axis of adult chimeric-transgenic mice results in a slowing of cellular migration without an apparent change in the distribution of terminal differentiation markers. A normal steady-state cellular census is maintained despite increases in apoptosis and reductions in proliferation within the crypt. Figure 7 compares this phenotype with the phenotype produced by forced expression of a dominant-negative NCAD $\Delta$ mutant in the same cellular populations. Figure 7 also presents a hypothesis that cadherin and catenin complexes, free catenins, and APC and catenin complexes operate in a continuum to regulate intestinal epithelial homeostasis. The adenomatosis polyposis coli $(\mathrm{APC})$ protein and E-cadherin are unable to associate with one another but both bind $\beta$-catenin $/ \mathrm{Su}$ et al. 1993; Rubinfeld et al. 1993, 1995). Cell culture studies indicate that a dynamic equilibrium exists between $E$-cadherin and $\beta$-catenin complexes, free pools of catenins, and APC and $\beta$-catenin complexes (Hinck et al. 1994; Jou et al. 1995). We postulate that shifting such an equilibrium toward E-cadherin and catenin complexes in the intestinal epithelium can produce decreased migration rates (increased adhesion) and decreased proliferation. In contrast, shifting the equilibrium toward free catenin pools or APC and catenin complexes can produce increased migration rates, increased proliferation, and increased death (shortened survival).

\section{Modulation of adhesion and migration}

Cell surface adhesion molecules help control migration because they couple interactions with the substratum (typically the extracellular matrix) to the cytoskeleton's motility apparatus (Huttenlocher et al. 1995). The intestinal epithelium faces a complex agenda. It must maintain tight cell-cell contacts so that it can function as an effective biological barrier. At the same time, it has to support constant, orderly, and rapid $(\sim 1$ cell diam. $/ \mathrm{hr})$ movement of differentiating and differentiated cell lineages. Thus, this epithelium provides an opportunity to explore the mechanisms by which cadherins $(1)$ endow a cell with the capacity to adhere tightly to its neighbor and (2) modulate migration over a substratum.

The results obtained with $\mathrm{B} 6 \leftrightarrow 129 / \mathrm{Sv}-\mathrm{ECAD}$ and B6 $\leftrightarrow 129 / \mathrm{Sv}-\mathrm{NCAD} \Delta$ chimeras and Fabpi-ECAD transgenic mice provide direct in vivo evidence that cell migration is influenced by cadherin-associated functions. Remarkably, slowing the rate of migration of 129 / Sv-ECAD cells does not produce a change in the organization of their migration. Cells continue to exit crypts and move in sharply demarcated vertical coherent columns up an adjacent villus. The more mobile B 6 cells do not overpopulate polyclonal villi so as to produce attenuation or extinction of $129 / \mathrm{Sv}-$ ECAD cellular columns. These observations suggest that intestinal epithelial cells may be able to specify their own migratory pathways, although the nature of the guidance molecules remains unclear.

The slowed migration associated with forced expression of E-cadherin in villus enterocytes is accompanied by increased steady-state levels of $\alpha$ - and $\beta$-catenin without a detectable change in their intracellular location,
Figure 7. Summary of the consequences of forced expression of E-cadherin or a dominant-negative $\mathrm{N}$-cadherin mutant along the crypt-villus axis of adult mice. The same Fabpl promoter was used to drive expression of ECAD and NCAD $\Delta$. The phenotype of $\mathrm{B} 6 \leftrightarrow 129 / \mathrm{Sv}-\mathrm{NCAD} \Delta$ mice is described in Hermiston and Gordon (1995b). The schematic view of the crypt-villus unit was adapted from Podolsky and Babyatsky (1991).
A PHENOTYPES:

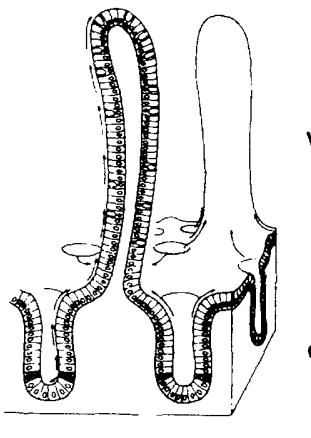

Forced Expression:

ECAD

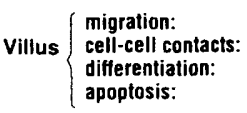

slowed but orderly no detectable change no detectable change no detectable change

\section{NCAD $\Delta$}

accelerated, disorganized disrupted increased loss of polarity, dysplasia, neoplasia

B MODEL:

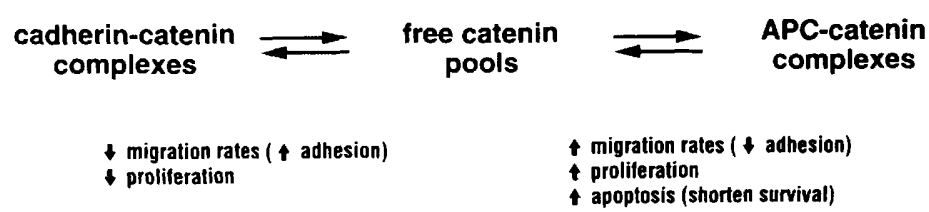


suggesting a shift toward functional E-cadherin and catenin complexes. The accelerated migration and reduced adhesiveness produced by forced expression of the dominant-negative NCAD $\Delta$ mutant is also accompanied by a redistribution and loss of endogenous E-cadherin and $\beta$-catenin without detectable changes in $\alpha$-catenin. This is consistent with a shift in the equilibrium away from E-cadherin and catenin complexes toward free catenin pools or APC and catenin complexes. To date we have not been able to determine the location of APC within the intestinal epithelium. However, on the basis of the $\mathrm{NCAD} \Delta$ phenotype, we predict that increasing APC levels will result in accelerated cell migration and/or disturbances in the orderliness of migration.

Free pools of $\beta$-catenin may have critical signaling functions in crypt-villus units

Forced expression of NCADS in the crypt increases proliferation, whereas forced expression of ECAD has the opposite effect. Neither protein alters the proliferative status of villus epithelial cells. The intracellular distribution of endogenous cadherins and catenins differs in crypts compared to villus epithelial cells, raising a question about the relationship between the location of these proteins and the sensitivity of the cells to cadherin- or catenin-mediated control of proliferative status. An additional question is whether the proliferative effects of NCAD $\triangle$ and ECAD are related directly to their effects on cellular adhesion or whether cadherin-associated molecules have independent signaling functions. Genetic studies indicate that $\beta$-catenin is involved in a Wnt/wingless signal transduction cascade that controls axis formation in early Xenopus and Drosophila embryos (McCrea et al. 1993; Heasman et al. 1994; Peifer et al. 1994; Peifer 1995). In Xenopus, $\beta$-catenin mutants with disabled adhesive activity retain their axis-inducing activity, indicating that the targets of $\beta$-catenin signaling include cellular functions that are separable from those that regulate adhesion (Funayama et al. 1995). The equilibrium alluded to in Figure 7 appears to affect the activity of this signaling pathway. Axis duplication produced by augmented $\beta$-catenin production can be blocked by coexpression of C-cadherin (Heasman et al. 1994). This results in sequestration of normal pools of $\beta$-catenin, rendering the protein unavailable for signaling. Comparable results have been obtained in Drosophila (Peifer et al. 1994; Peifer 1995). Augmentation of cytosolic pools of the $\beta$-catenin homolog Armadillo results in transduction of a signal through an analogous pathway that regulates posterior cell fates and axial patterning.

There are several reasons for suggesting that a Wntmediated, $\beta$-catenin-dependent signaling pathway may function as a modulator of proliferative status in crypt cells. (1) NCAD $\Delta$ produces increased cytosolic $\beta$-catenin and hyperproliferative crypts. Forced expression of E-cadherin produces hypoproliferative crypts, which could reflect decreased free catenin or the availability of APC and catenin complexes. (2) Ectopic expression of Wnt-1 in transgenic mice enhances cell proliferation
(Dickinson et al. 1994). Wnt-1 also increases accumulation of $\beta$-catenin and its homolog plakoglobin (Bradley et al. 1993; Hinck et al. 1994). (3) NCAD $\Delta$ expression leads to neoplasia in the intestinal epithelium. A mutant APC with a carboxy-terminal truncation also initiates development of intestinal neoplasms in Min mice (Su et al. 1992). Expression of wild-type APC in a human colon carcinoma cell line causes increased turnover and a reduced steady-state level of cytosolic $\beta$-catenin (Munemitsu et al. 1995). The region of APC that effects this down-regulation of $\beta$-catenin is absent or truncated in tumors containing APC gene mutations, including $A p c^{\mathrm{Min}}$ (Munemitsu et al. 1995; Polakis 1995). Thus, augmenting $\beta$-catenin pool size or influencing its cytosolic distribution, whether through activation of a Wnt pathway, from loss of the carboxyl terminus of APC, or from forced expression of NCAD $\Delta$, may lead to enhanced or unrestrained proliferation within the crypt environment.

\section{Cell death}

Forced expression of E-cadherin induces an apoptotic response that was most prominent in the upper third of the crypt and entirely absent from the villus (Fig. 7). In contrast, the increased apoptosis accompanying NCADS production was distributed uniformly throughout the crypt-villus axis. These patterns are distinct from the responses to other stimuli that are applied to crypt-villus units. For example, irradiation evokes an apoptotic response that is predominantly confined to the stem cell zone (cell stratum 4-6 from the crypt base) and absent from the villus (Potten 1992). The mechanisms responsible for the different distributions of apoptotic cells in $\mathrm{NCAD}^{+}, \mathrm{ECAD}^{+}$, or irradiated crypt-villus units are unknown. However, the observations suggest that death along the crypt-villus axis may reflect the activation of different programs that, in turn, fulfill unique functions in response to specific insults to different domains of the crypt-villus continuum.

\section{Considering the environment}

The different distributions of apoptotic cells in 129/SvECAD and $129 / \mathrm{Sv}-\mathrm{NCAD} \Delta$ crypts and the different proliferative responses of crypt and villus epithelial cells to NCAD $\Delta$ production underscore an important point about the consequences of altering the equilibrium described in Figure 7 . The phenotype that predominates in the continuum between (1) adhesion and migration or (2) proliferation and death may be influenced profoundly by the cellular context (environment) in which the equilibrium is established. The availability and activity of other cellular signaling pathways can affect cadherin and catenin or APC and catenin complexes (for review, see Hoschuetzky et al. 1994; Shibamoto et al. 1994). Environmental modulation of these complexes could mean that in some cellular contexts a given equilibrium will produce a predominant phenotype of death whereas in other contexts, the same equilibrium will produce a predomi- 
nant phenotype of altered migration without any effect on apoptosis.

\section{Prospectus: using polyclonal crypt-villus units to assay the functions of cadherins and their associated proteins}

The juxtaposition of normal and genetically manipulated cells in polyclonal crypt-villus units, where the themes of proliferation, migration, adhesion, differentiation, and death are continuously played out, provides an attractive experimental setting to further assess the consequences of disrupting cadherin and catenin function. The assay system is sensitive. For example, the polyclonal villi of chimeric mice allowed us to identify the disorganized migration that accompanies NCADد expression. This phenotype was not accompanied by changes in villus dimensions and would be difficult to appreciate in transgenic animals where all epithelial cells in a crypt-villus unit have a similar genotype. Similarly, polyclonal villi allowed us to define changes in the distance cells migrate over time by comparing adjacent columns of normal B6 and genetically manipulated 129/ Sv cells. We believe that such a comparison is the most accurate way currently available for documenting alterations in the speed of migration. (1) Real-time visualization of cell movement in living material would represent a true measure of migration rates but is not yet possible. (2) There are enormous technical difficulties in trying to obtain samples from the same region of a single living mouse's duodenal-ileal axis 12-96 hr after a BrdU pulse. (3) The gut epithelium cannot be studied reliably ex vivo as it undergoes a rapid demise.

The polyclonal villus can be used for additional mechanistic studies. For example, the polyclonal villi of B6 $\leftrightarrow 129 /$ Sv-ECAD and B6 $\leftrightarrow 129 /$ Sv-NCADد chimeras should allow a migratory phenotype to be correlated with the status of components of the focal adhesion complex (Huttenlocher et al. 1995). In addition, the consequences of forced expression of APC or $\beta$-catenin can be used to test the model presented in Figure 7.

\section{Materials and methods}

Studies of chimeric mice

Generation of chimeras A 2.9-kb EcoRI fragment, containing nucleotides -596 to +21 of rat Fabpl linked to nucleotides +3 to +2150 of the human growth hormone (hGH) gene, was placed at the EcoRI site of pPgkNeoBS (Hermiston and Gordon 1995a), yielding pL596hGHDon. This positioned Fabpl-hGH upstream and in the same transcriptional orientation as a $p g k$ Neo selection cassette. The hGH gene contains a BamHI site at its nucleotide +3. pL596hGHDon has two additional BamHI sites, one located $3^{\prime}$ to $p g k N e o$ and the other in the pBluescript polylinker 5' to Fabpl-hGH. These two BamHI sites were eliminated, yielding pL596hGHpNEO $\Delta \mathrm{B}_{2}$. pSK + UM (kindly provided by Rolf Kemler, Max-Planck Institute for Immunobiology, Freiburg, Germany) contains a mouse E-cadherin cDNA. The ECAD DNA was excised with HindIII and BgIII. The Hin. dIII overhang was filled in with Klenow. BglII linkers were added, and the $2.7 \cdot \mathrm{kb}$ fragment was subcloned into the $\mathrm{BamHI}$ site of pL596hGHpNeosB 2 , generating pLECAD. The FabplECAD-hGH-pgkNeo (LECAD) insert was liberated with $X b a \mathrm{I}$, purified, and electroporated into D3 ES cells. Two independent D3-LECAD cell lines were injected into B6 blastocysts $\{10-15$ ES cells/blast) to generate $\mathrm{B} 6 \leftrightarrow 129 /$ Sv-LECAD chimeras.

B6 $\leftrightarrow 129 /$ Sv-NCAD $J$ chimeras were produced using D3 ES cells transfected with a construct analogous to LECAD except that it contained NCADS at the BamHI site (Hermiston and Gordon 1995b). Control B6 $\leftrightarrow 129 / \mathrm{Sv}$ animals were produced using nontransfected D3 ES cells.

All mice were maintained in microisolator cages in a barrier facility under a strictly controlled light cycle and fed a standard irradiated chow diet (Pico Lab Rodent Diet 20, PMI Feeds) ad libitum. A sentinel screening program as well as serological tests of blood obtained at time of sacrifice indicated that all animals were free of pathogens.

Intestinal whole-mount preparations Whole mounts were prepared according to Hermiston et al. (1993) except that the tissues were fixed in paraformaldehyde-lysine-periodate (PLP) for $30 \mathrm{~min}$, and endogenous peroxidase activity was blocked by incubation in $1 \% \mathrm{H}_{2} \mathrm{O}_{2} /$ methanol for $15 \mathrm{~min}$. The whole mounts were then stained with peroxidase-conjugated UEAl.

Single and multilabel immunohistochemical analyses Mice were given a single intraperitoneal injection of BrdU (Sigma; $120 \mathrm{mg} / \mathrm{kg}$ body weightl and 5 -fluoro- $2^{\prime}$-deoxyuridine (Sigma; $12 \mathrm{mg} / \mathrm{kg} \mid 1.5,24,48,60,72$, or $96 \mathrm{hr}$ before sacrifice. The entire gastrointestinal tract was removed en bloc immediately after sacrifice, flushed with ice-cold phosphate-buffered saline, fixed in Bouin's solution for 6-12 hr or PLP for $30 \mathrm{~min}$, and then washed with $70 \%$ ethanol. Swiss rolls (Hermiston et al. 1993) were prepared from the proximal third of the small intestine, embedded in paraffin, and sectioned.

The methods used for single and multilabel immunohistochemical staining are described elsewhere (Roth et al. 1990; Falk et al. 1994; Hermiston and Gordon 1995al. The following antisera were used: goat anti-BrdU (Cohn et al. 1992), mouse anti-actin (Sigma), rabbit anti-rat L-FABP (Roth et al. 1990), rabbit anti-I-FABP (Cohn et al. 1992), rabbit anti-serotonin (Incstar), rabbit anti-substance P (Roth and Gordon 1990), rabbit anti-secretin (Peninsula Laboratories), sheep anti-human lysozyme (Dako), rabbit anti-mouse cryptdin-1 (Bry et al. 1994), rabbit anti-pan-cadherin (Sigma), rabbit anti-laminin (Sigma), rabbit anti-type IV collagen (Collaborative Biomedical Products), rabbit anti-mouse fibronectin (Chemicon), rabbit antiheparin sulfate proteoglycan (Chemicon), and rat monoclonal antibodies (mAbs) to ZO-1 (Chemicon). Frozen sections were incubated with rat E-cadherin mAbs /Vestweber and Kemler 1985; obtained from Rolf Kemlerl, rabbit anti- $\beta$-catenin sera, or affinity purified rabbit $\alpha$-catenin antibodies (Näthke et al. 1994; kindly provided by lnke Näthke and James Nelson).

Five lectins were used: peroxidase-, biotin-, or fluorescein isothiocyanate (FITC)-conjugated UEAI (Sigma), D. biflorus agglutinin (Sigma), H. pomentia agglutinin (Sigma), Jacalin (Artrocarpus integrifolia agglutinin; EY-Labs), and soybean (G. $\max$ ) agglutinin (Sigma).

Quantitation of mitosis and apoptosis Mitotic and apoptotic events were scored on $\mathrm{H} \& \mathrm{E}$-stained sections of paraffin-embedded Swiss rolls. Serial sections were stained with $\mathrm{H} \& \mathrm{E}$ and peroxidase-conjugated UEA1 to genotype adjacent patches of $129 /$ Sv- and B6-derived epithelium. Adjacent B6 and 129/Sv patches were counted in the proximal third of the small intestine. Five 
to ten well-oriented intact crypt-villus units were scored per patch. Approximately $100129 / \mathrm{Sv}$ and B6 crypt-villus units were scored per chimera. Four to six mice were examined per cell line and the data pooled to define the mean number of events per B6 or $129 /$ Sv crypt section \pm S.E. The significance of differences between B6 and 129/Sv crypt-villus units was evaluated using Student's $t$ test (SigmaPlot).

The position of each mitotic or apoptotic event was recorded. Crypts were divided into lower, middle, and upper thirds and villi were treated as a single unit. Apoptotic cells were identified using standard morphologic criteria (Hall et al. 1994). Defining apoptosis by these criteria gave results that were equivalent to detection based on TUNEL assays (Gavrieli et al. 1992; Hall et al. 1994; Hermiston and Gordon 1995a).

\section{Studies of Fabpi-ECAD transgenic mice}

Generation of transgenic animals ECAD DNA was excised from pSK + UM with HindIII and BgIII. The HindIII overhang was filled in with Klenow, BglII linkers were added and the $2.7-\mathrm{kb}$ fragment was subcloned into the BamHI site of pIl 178hGHpNEO $\Delta \mathrm{B}_{2}$ (Hermiston and Gordon 1995a), generating pIECAD. A 6.2-kb Fabpi-ECAD-hGH-pgkNeo fragment (IECAD) was excised from pIECAD with $\mathrm{XbaI}$ and Sall and injected into FVB/N oocytes. Five founder transgenics were identified from the 43 liveborn mice that were screened. Pedigrees were established from four of these mice by crosses to normal $\mathrm{FVB} / \mathrm{N}$ littermates.

Specific pathogen-free transgenic mice and their nontransgenic littermates were maintained in microisolator cages in the same rodent barrier facility as the chimeric-transgenic animals and given the same irradiated chow diet. Mice were killed at 2-10 months of age by cervical dislocation. An intraperitoneal injection of $\mathrm{BrdU}$ was given $1.5,24,48,60,72$, or $96 \mathrm{hr}$ before sacrifice $(n=2-4$ mice/time point $)$.

Quantitation of apoptotic and M-phase cells Swiss rolls were prepared from the proximal third of the small intestine. Fivemicron-thick paraffin sections were stained with H\&E and $M$-phase and apoptotic cells were counted in 100 well-oriented crypt-villus units per mouse $(n=10$ transgenics and 14 normal littermates). All counting was done in double-blind fashion by two observers.

Western blot analysis of E-cadherin and catenin levels Total protein extracts were prepared from the proximal third of transgenic and normal littermate small intestine according to Crossman et al. (1994). Solubilized tissue protein $(100 \mu \mathrm{g})$ was fractionated by electrophoresis through $10 \%$ polyacrylamide gels containing 0.1\% SDS (Laemmli 1970). Separated proteins were transferred to polyvinylidene difluoride membranes (Amersham). Blots were incubated at room temperature for $1 \mathrm{hr}$ with (1) E-cadherin mAbs, (2) rabbit anti- $\beta$-catenin sera, or $(3 \mid$ affinity-purified rabbit anti- $\alpha$-catenin. Antigen-antibody complexes were detected using the Western Light ${ }^{\text {TM }}$ kit (Tropix). Blots were then stripped and reprobed with rabbit polyclonal antibodies to actin (Sigma). Autoradiographs of the blots were scanned with a densitometer. Only signals in the linear range of film sensitivity were used to quantitate steady-state levels of each protein.

\section{Acknowledgments}

We thank David O'Donnell and Maria Karlsson for expert technical assistance, Chitra Chandrasekaran for help in quantitating proliferating and apoptotic cells in transgenic mice, and Rolf Kemler, Inke Näthke, and James Nelson for supplying us with reagents. This work was supported in part by grants from the National Institutes of Health (DK37960 and DK30292).

The publication costs of this article were defrayed in part by payment of page charges. This article must therefore be hereby marked "advertisement" in accordance with 18 USC section 1734 solely to indicate this fact.

\section{References}

Bradley, R.S., P. Cowin, and A.M. Brown. 1993. Expression of Wnt-1 in PCl2 cells results in modulation of plakoglobin and E-cadherin and increased cellular adhesion. J. Cell Biol. 123: 1857-1865.

Bry, L., P. Falk, K. Huttner, A. Ouellette, T. Midtvedt, and J.I. Gordon. 1994. Paneth cell differentiation in the developing intestine of normal and transgenic mice. Proc. Natl. Acad. Sci. 91: 10335-10339.

Calvert, R. and P. Pothier. 1990. Migration of fetal intestinal intervillous cells in neonatal mice. Anat. Rec. 227: 199-206.

Cheng, H. 1974. Origin, differentiation and renewal of the four main epithelial cell types in the mouse small intestine. IV. Paneth cells. Am. I. Anat. 141: 521-536.

Cohn, S. M., T.C. Simon, K.A. Roth, E.H. Birkenmeier, and J.I. Gordon. 1992. Use of transgenic mice to map cis-acting elements in the intestinal fatty acid binding protein gene (Fabpi) that control its cell lineage-specific and regional patterns of expression along the duodenal-colonic and cryptvillus axes of the gut epithelium. /. Cell Biol. 119: 27-44.

Crossman, M.W., S.M. Hauft, and J.I. Gordon. 1994. The mouse ileal lipid binding protein gene: A model for studying axial patterning during gut morphogenesis. I. Cell Biol. 126: $1547-1564$.

Dickinson, M.E., R. Krumlauf, and A.P. McMahon. 1994. Evidence for a mitogenic effect of Wnt-l in the developing mammalian central nervous system. Development 120: $1453-1471$.

Falk, P., K.A. Roth, and J.I. Gordon. 1994. Lectins are sensitive tools for defining the differentiation programs of mouse gut epithelial cell lineages. Am. I. Physiol. (Gastrointest. Liver Physiol.| 266: G987-G1003.

Funayama, N., F. Fagotto, P. McCrea, and B.M. Gumbiner. 1995. Embryonic axis induction by the armadillo repeat domain of $\beta$-catenin: Evidence for intracellular signaling. I. Cell Biol. 128: 959-968.

Gavrieli, Y., Y. Sherman, and S.A. Ben-Sasson. 1992. Identification of programmed cell death in situ via specific labeling of nuclear DNA fragmentation. I. Cell Biol. 119: 493-501.

Haegel, H., L. Larue, M. Ohsugi, L. Fedorov, K. Herrenknecht, and R. Kemler. 1995. Lack of $\beta$-catenin affects mouse development at gastrulation. Development 121: 3529-3537.

Hall, P.A., P.J. Coates, B. Ansari, and D. Hopwood. 1994. Regulation of cell number in mammalian gastrointestinal tract: the importance of apoptosis. I. Cell Sci. 107: 3569-3577.

Heasman, I., A. Crawford, K. Goldstone, P. Garner-Hamrick, B. Gumbiner, P. McCrea, C. Kintner, C.Y. Noro, and C. Wylie. 1994. Overexpression of cadherins and underexpression of $\beta$-catenin inhibit dorsal mesoderm induction in early Xenopus embryos. Cell 79: 791-803.

Hermiston, M.L. and J.I. Gordon. 1995a. In vivo analysis of cadherin function in mouse small intestinal enterocytes: Essential role in adhesion, maintenance of differentation, and regulation of programmed cell death. I. Cell Biol. 129: 489-506. 1995b. Inflammatory bowel disease and adenomas in mice expressing a dominant negative $\mathrm{N}$-cadherin. Science 
270: 1203-1207.

Hermiston, M.L., R.P. Green, and J.I. Gordon. 1993. Chimerictransgenic mice represent a powerful tool for studying how the proliferation and differentiation programs of intestinal epithelial cell lineages are regulated. Proc. Natl. Acad. Sci. 90: 8866-8870.

Hinck, L., I.S. Näthke, J. Papkoff, and W.J. Nelson. 1994. Dynamics of cadherin/catenin complex formation: Novel protein interactions and pathways of complex assembly. I. Cell Biol. 125: 1327-1340.

Hoschuetzky, H., H. Aberle, and R. Kemler. 1994. B-Catenin mediates the interaction of the cadherin-catenin complex with epidermal growth factor receptor. J. Cell Biol. 127: 13751380 .

Huttenlocher, A., R.R. Sandborg, and A.F. Horwitz. 1995. Adhesion in cell migration. Curr. Opin. Cell Biol. 7: 697-706.

Jou, T.-S., D.B. Stewart, J. Stappert, W.J. Nelson, and J.A. Marrs. 1995. Genetic and biochemical dissection of protein linkages in the cadherin-catenin complex. Proc. Natl. Acad. Sci. 92: 5067-5071.

Kim, S.H., K.A. Roth, A.R. Moser, and J.I. Gordon. 1993. Transgenic mouse models that explore the multistep hypothesis of intestinal neoplasia. J. Cell Biol. 123: 877-893.

Kintner, C. 1992. Regulation of embryonic cell adhesion by the cadherin cytoplasmic domain. Cell 69: 225-236.

Laemmli, U.K. 1970. Cleavage of structural proteins during the assembly of the head of bacteriophage T4. Nature 227: 680685.

Larue, L., M. Ohsugi, J. Hirchenhain, and R. Kemler. 1994. E-cadherin null mutant embryos fail to form a trophectoderm epithelium. Proc. Natl. Acad. Sci. 91: 8263-8267.

McCrea, P., W.M. Brieher, and B.M. Gumbiner. 1993. Induction of a secondary body axis in Xenopus embryos by antibodies to $\beta$-catenin. I. Cell Biol. 123: 477-485.

Munemitsu, S., I. Albert, B. Souza, B. Rubinfeld, and P. Polakis. 1995. Regulation of intracellular $\beta$-catenin levels by the adenomatous polyposis coli (APC) tumor-suppressor protein. Proc. Natl. Acad. Sci. 92: 3046-3050.

Nagafuchi, A. and M. Takeichi. 1988. Cell binding function of E-cadherin is regulated by the cytoplasmic domain. EMBO $/$. 7: 3679-3684.

Näthke, I.S., L. Hinck, J.R. Swedlow, J. Papkoff, and W.J. Nelson. 1994. Defining interactions and distributions of cadherin and catenin complexes in polarized epithelial cells. $/$. Cell Biol. 125: 1341-1352.

Overduin, M., T.S. Harvey, S. Bagby, K.I. Tong, P. Yau, M. Takeichi, and M. Ikura. 1995. Solution structure of the epithelial cadherin domain responsible for selective cell adhesion. Science 267: 386-389.

Ozawa, M., H. Baribault, and R. Kemler. 1989. The cytoplasmic domain of the cell adhesion molecule uvomorulin associates with three independent proteins structurally related in different species. EMBO I. 8: 1711-1717.

Ozawa, M., M. Ringwald, and R. Kemler. 1990. Uvomorulincatenin complex formation is regulated by a specific domain in the cytoplasmic region of the cell adhesion molecule. Proc. Natl. Acad. Sci. 87: 4246-4250.

Pfeifer, M. 1995. Cell adhesion and signal transduction: The Armadillo connection. Trends Cell Biol. 5: 224-229.

Pfeifer, M., D. Sweeton, M. Casey, and E. Wieschaus. 1994. Wingless signal and zeste-white 3 trigger opposing changes in the intracellular distribution of Armadillo. Development 120: $369-380$.

Podolsky, D.K. and M.W. Babyatsky. 1991. Growth and development of the gastrointestinal tract. In Textbook of gastroenterology (ed. T. Yamada, D.H. Alpers, C. Owyang, D.W
Powell, and F.E. Silverstein|, Vol. 1, p. 489. J.B. Lippincott, Philadelphia, PA.

Polakis, P. 1995. Mutations in the APC gene and their implications for protein structure and function. Curr. Opin. Genet. Devel. 5: 66-71.

Potten, C.S. 1992. The significance of spontaneous and induced apoptosis in the gastrointestinal tract of mice. Cancer Metast. Rev. 11: 179-195.

Potten, C.S. and M. Loeffler. 1990. Stem cells: Attributes, cycles, spirals, pitfalls and uncertainties. Lessons for and from the crypt. Development 110: 1001-1020.

Riethmacher, D., V. Brinkmann, and C. Birchmeier. 1995. A targeted mutation in the mouse E-cadherin gene results in defective preimplantation development. Proc. Natl. Acad. Sci. 92: 855-859.

Roskelley, C.D., A. Srebrow, and M.J. Bissell. 1995. A hierarchy of ECM-mediated signalling regulates tissue-specific gene expression. Curr. Opin. Cell Biol. 7: 736-747.

Roth, K.A. and J.I. Gordon. 1990. Spatial differentiation of the intestinal epithelium: Analysis of enteroendocrine cells containing immunoreactive serotonin, secretin, and substance $\mathrm{P}$ in normal and transgenic mice. Proc. Natl. Acad. Sci. 87: 6408-6412.

Roth, K.A., J.M. Hertz, and J.I. Gordon. 1990. Mapping enteroendocrine cell populations in transgenic mice reveals an unexpected degree of complexity in cellular differentiation within the gastrointestinal tract. $/$. Cell. Biol. 110: 17911801.

Rubinfeld, B., B. Souza, I. Albert, O. Müller, S.H. Chamberlain, F.R. Masiarz, S. Munemitsu, and P. Polakis. 1993. Association of the APC gene product with $\beta$-catenin. Science 262: $1731-1734$.

Rubinfeld, B., B. Souza, I. Albert, S. Munemitsu, and P. Polakis. 1995. The APC protein and E-cadherin form similar but independent complexes with $\alpha$-catenin, $\beta$-catenin, and plakoglobin. I. Biol. Chem. 270: 5549-5555.

Schmidt, G.H., D.J. Winton, and B.A.J. Ponder. 1988. Development of the pattern of cell renewal in the crypt villus unit of chimeric mouse intestine. Development 103: 785-790.

Shapiro, L., A.M. Fannon, P.D. Kwong, A. Thompson, M.S. Lehmann, G. Grübel, J.-F. Legrand, J. Als-Nielsen, D.R. Colman, and W.A. Hendrickson. 1995. Structural basis of cell-cell adhesion by cadherins. Nature 374: 327-386.

Shibamoto, S., M. Hayakawa, K. Takeuchi, T. Hori, N. Oku, K. Mayazawa, N. Kitamura, M. Takeichi, and F. Ito. 1994. Tyrosine phosphorylation of $\beta$-catenin and plakoglobin enhanced by hepatocyte growth factor and epidermal growth factor in human carcinoma cells. Cell Adhesion Commun. 1: $295-305$.

Su, L.-K., B. Kinzler, B. Vogelstein, A.C. Preisinger, A.R. Moser, C. Luongo, K.A. Gould, and W.F. Dove. 1992. Multiple intestinal neoplasia caused by a mutation in the murine homolog of the APC gene. Science 256: 668-670.

Su, L.-K., B. Vogelstein, and K.W. Kinzler. 1993. Association of the APC tumor suppressor protein with catenins. Science 262: 1734-1737.

Trahair, J., M. Neutra, and J.I. Gordon. 1989. Use of transgenic mice to study the routing of secretory proteins in intestinal epithelial cells: Analysis of human growth hormone compartmentation as a function of cell type and differentiation. I. Cell Biol. 19: 3231-3242.

Vestweber, D. and R. Kemler. 1985. Identification of a putative cell adhesion domain of uvomorulin. EMBO /. 4: 3393-3398.

Wright, N.A. and M. Irwin. 1982. The kinetics of villus cell populations in the mouse small intestine: Normal villi-the steady state requirement. Cell Tiss. Kinet. 15: 595-609. 


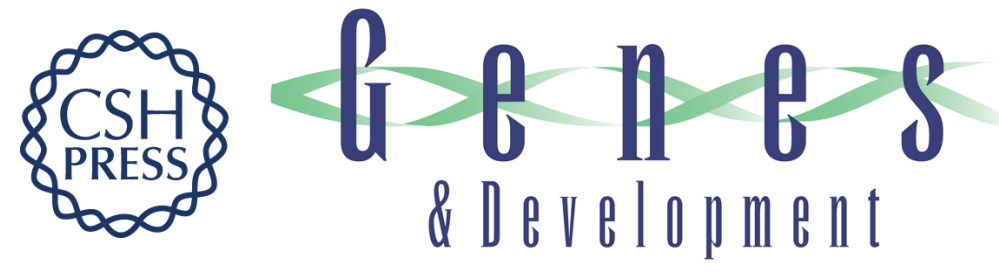

\section{Forced expression of E-cadherin in the mouse intestinal epithelium slows cell migration and provides evidence for nonautonomous regulation of cell fate in a self-renewing system.}

M L Hermiston, M H Wong and J I Gordon

Genes Dev. 1996, 10:

Access the most recent version at doi:10.1101/gad.10.8.985

References This article cites 50 articles, 32 of which can be accessed free at: http://genesdev.cshlp.org/content/10/8/985.full.html\#ref-list-1

License

Email Alerting Service

Receive free email alerts when new articles cite this article - sign up in the box at the top right corner of the article or click here.

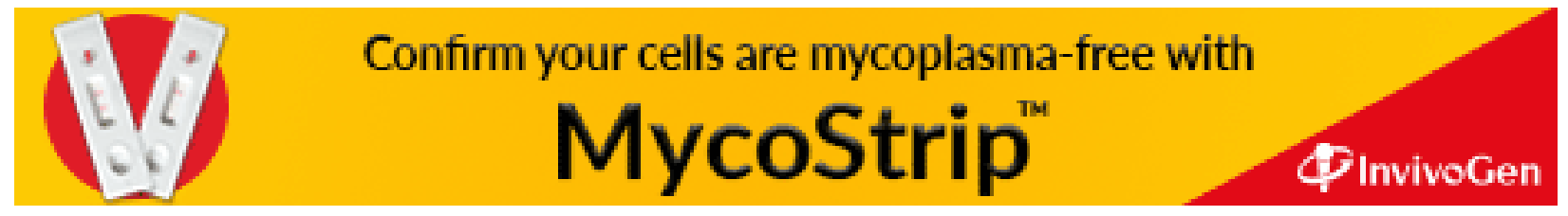

